\title{
Dichotomous options in Earth Sciences Education: brief reflection
}

\author{
Paulo C. Soares
}

Earth Sciences, Federal University of Parana. Curitiba (Brazll). E-mall: P soares@iterra.com.br

Abstract:The explosion and dissemination of knowledge and technologies is one of the characteristics of the current time. The teacher is no longer the reference of knowledge or competence. The expansion and deepening of concepts and methods grow exponentially. Knowledge does not provide a clear path to future life success. Earth-related issues are global sustainability concerns. Now, the claim is to pick up and deal with the information to solve specific problems. The expert apps have become powerful tools for learning and professional operations. There is a new student with different problems, social environment and motivations, especially his appreciation for autonomy, in an immense diversity of offers and demands. And there is new ways to learn, more friendly but more away from the real world. What does this change in the curricula and for the teacher and student in the classroom? Two opposite answers are the common behavior: focus on teaching or focus on learning. In the first, good teachers will look for the best subjects, based on gaps and remarkable discoveries and good examples in the body of scientific knowledge and attractive ways of presenting them to students. In the second, good teachers will help and guide students to organize and work to find the most appropriate and motivating issues and ways to deal with them to be useful in their lives. Earth sciences have many problems, solutions and challenges, daily in the news and in the surroundings of place and student life. Students become proud to be active in the group, in his real world, according to his needs, his challenges; and they need help and guidance in this process. Teachers will focus on the motivations of these students to build their knowledge, their being, their skills, their professional abilities, their commitments as citizens and the reasons to lifelong learning.

\section{Introduction}

The extension, deepening and diffusion of knowledge, conceptual and technological, is a surprising characteristic of the present time. It has followed digital technology for the past fifty years and is a promise for the future. In any small town, in the field or in any neighborhood of a big city or with a phone or a tablet it is possible to access the knowledge stored in international centers, universities, libraries and depositories, encyclopedias, articles, lecture notes, circles of discussions, reviews of reputable connoisseurs, with variable degree of depth. The teacher is no longer the reference of knowledge.

The students themselves realize this because they know there are better classes about a subject in well consolidating educational sites in the internet. The importance attributed to teacher knowledge by students is a fraction (7\%) of the importance of relating well (trusting, caring professionalism, 35\%) (data from Global Survey on teacher effectiveness /www.pearson.com, McKnight et al. 2016). Knowing "what" is this or that, or "who" did this or that, or "when" or "where", is no longer a personal advantage. These are the kind of information that is easily found with the smartphone.

We no longer need to understand Cosmology to determine the exact geographical position of a reference point, the astronomical point. Or learn the trigonometric theory and effects and projection techniques to build a block diagram; or to access integrals and derivatives to determine tensions, or volumes, or flow in a reservoir; or the correlation, or geochemistry classification, or hundreds of other procedures of compulsory learning to any early student of Earth Sciences.

The Earth Sciences concepts, relations, techniques and methods duplicate at each ten years, reaching tens of thousands subjects today. This estimative of renewable halftime is similar to other consolidated sciences. The issue now is to know how to handle critically the information in order to solve problems or to create a utility or to explain and transform the environment: its meaning, its implications, its thresholds. This is what is considered knowledge, for a book contains information, but not knowledge, the capability to use the information. 
It is also imperative how to navigate critically within the big world of information in this knowledge society. So, for the knowledge society, it is imperative to learn how to navigate, how to access, how to test, and how to critically appropriate information and the tools to use. The multiplication and dissemination of specialist software systems has become a powerful learning and professional tool. And at each new time more friendly usable.

The multiplication and dissemination of specialist software systems has become a powerful learning and professional tool. We do not need any more to understand Cosmology to determine the exact geographical position of a reference point, the astronomical point. Or learn the trigonometric theory and effects and projection techniques to build a block diagram; or to access integrals and derivatives to determine tensions, or volumes, or flow in a reservoir; or the correlation, or geochemistry classification, or hundreds of other procedures of compulsory learning to any early student of Earth Sciences.

There is no doubt about it. In the past, to construct a diagram we had to learn how to fold planes. In order to use kriging, we had to integrate the variance into a block by solving, for each one, its system of equations by matrix calculation. What we need now is to learn the usability of the more specific or appropriate application!

This availability and the usability of specialist software have reduced the demand for specialized understanding of chemistry, physics and mathematics. No need to learn difficult integral and differential or numerical calculus. Just learn what its usefulness and how to use in MatLab or some geo-referenced software!

Software use in the various fields, as in Geology, Geophysics, Meteorologyand Geography, has disproportionately increased the demand to learn new skills. So how many new tools or applications do we need to learn to use? Not so much knowledge about how the application was conceived and built, but how it works, where it is applied, how it is used, how one critically analyze, and validate its results.

The big challenge for the student and teacher, limited by the inability to learn and master all content and tools, is "what to learn"? The answer has two components: 1) learning how to learn; 2 ) start with the problems. The basic principle is motivation and preparation for learning in order to benefit from the available knowledge outside the class room, home or service (Knowles et al. 1998,
Houde 2006). Other changes in the profile of society help us to prove the choice of alternatives. They are not news but are neglected. The purpose of this analysis is to characterize this dramatic bifurcation in the development of education, considering some situations in which two education currents follow diverse paths in focus, goal and method. The rationale developed points to the prevalence of a revolutionary, if not new, way of teaching and learning in Earth Sciences. Note: although not a scientific argument, for some of the assertions presented, the author tested and experimented with different modes of education, traditional and innovations for more than fifty years in various programs of adult literacy, basic education, technical, undergraduate, graduate and corporate courses.

\section{Some Challenges for Education in Earth Sciences}

The focus of teaching-learning, which had been used in a century of modernity, was the predominance of teaching content presented sequentially, year after year, class after class. Teacher is the master of certain content and his task is to pass this content from one room to another, class after class, using a succession of picture frames, illustrated and sometimes attractive. The student is a code, activated or not.

The teacher has mastery over what will happen to him in the classroom as protagonist and main actor, if not the only one, following the class script - contained in the textbook or summarized in the brochure. This content is required for class, or for the next semester or year, or for future admission tests. The passive student, with his back to the subject of the lesson, comes to his banalities: he does not know his future, neither the class nor the next term; nor does he have any expectation about the college entrance examination. Just want to know what the subject of the next test will be, to study in a timely manner.

Would the student be an object or a passive being that receive a set of signs that make no sense to him? Although they make sense for the professor which endure four or five years to "see" these contents and others even far away from reality. In such a way, educational system works with knowledge: how to divide it, organize it, and introduce sequenced knowledge into a student's life to transform it in terms of availability of knowledge, behavior and skills. 
It's a dull behavior, as it does not require intelligence from the professor nor student. Also does not require creativity. The assessment is done by the examination, a proof of acquired knowledge. As everyone knows, it tests certain fraction of content as "passed" by teacher.

But the teacher who discovers this dilemma as well as a trap, and makes attempts at change, faces resistance from colleagues and even students, because schools are poised for passivity, with tables and chairs lined up to promote order and individualization.

Could it be different? Yes, the focus could be learning.

\subsection{Focus on Teaching or Learning?}

This is the first dichotomy. The student-centered as apprentice, while a social active subject; that enables itself to transform and self-construct, instead of the student moved as object to be transformed. Best: focus on the construction of apprentice student, the student that motivates himself to learn, that learn how to learn, that become able to concord or discord, organize and work together, to be collaborative, to discuss, evaluate, take, share and to use contents, habits, and skills, thus incorporating them into his life, learning in group. Furthermore, for long time it is known that the easiest and effective way to learn is doing and as Galileo Galilei had realized: "nothing is taught except to learn".

This learning is done with changes in the neural circuitry of the student and the acceptance of these modifiers stimuli is crucial to learn. Passes through five levels of increasing complexity (Keys 2017, Usher 2013): (1) the feeling of something new, a change, a break with the established; (2) the perception, when the neural apparatus converts the sensations in impulses; (3) the formation of pictures and comparison with known images, resident in memory; (4) the symbolization, the representation of processes for symbolic sets, numbers, words; and (5) conceptualization, the mental process of establishing relationships and correlations, categorization, classification, etc. Doing that is a need to learn.

So, all teachers need to work dealing with this new focus: the real student who values the autonomy and likes to relate (Knowles et al. 1996, Freire 1996, Houde 2006), to be active in the group, in his real world, according to his needs, his challenges; and who needs help and guidance in this process. Teachers will focus on these students' motivations for the construction of his being, for learning. Learning for understanding the world that surrounds the student, a mutant world, threatening and threatened, around or accessible to the student; for his coexistence be improved and sustainable and for the acquisition of transformer skills, in progressively larger circles.

The contradiction between the two educational approaches is evident. The first is much easier, inexpensive, routine, automated, as mass production of the past. The second requires preparation, organization, management, control of time and momentum for each class, with intensive and intelligent effort and creativity in each class.

This second approach is very appropriate for the learning of Earth Sciences due to (1) the strong presence of objects and processes of nature around the student; (2) the important role of critical visual intelligence in the investigation and appropriation of knowledge; and (3) the extensive presence of knowledge arranged in provisory or temporary models, waiting for changes.

\subsection{The Reductionist X Holistic Knowledge in Earth studies}

The rationalism and the industrialization culture, in the past modern world, led us to think more easily in a reductionist transformation model of the student: he would be the raw material suitable for conventional teaching procedures be adopted in order to transform him into a new being, adapted to this industrial society, the society of consume and of encyclopedic and compartmented knowledge and technology.

The postmodern world and the new industrial revolution - digital and intelligent - have disrupted the boundaries of compartmented and reductionist knowledge (Trefil \& Hazen 1995). Transpose the knowledge to the clouds, even the specialized and up-to-date, at the disposition of students and professionals, at a click in the hands or in the pockets. The big challenge is how to access and qualify it, critically, appropriate and make it usable. This is the new phase in the history of mankind, mainly in an undeveloped society. The people don't need more to host the encyclopedic knowledge. And the teacher does not need to try to "pass" this already available knowledge: who, what, which, when. The challenge is relationship and usability: why, how, then! 
The mission of the school turns to be the creation of opportunities for students to develop in their different intelligences (Gardner 1983, 2011): rational, visual, musical, linguistic, social etc. The subdivision of disciplines and progressive reduction in the field of addressing the problems and natural objects tend to lose meaning. The multi-, inter-, trans-disciplinary knowledge and approach become more and more objective and effective.

The two models lead to different formulations for the curricular organization in Earth Sciences. In the first case, the Cartesian reductionist model there follows the known systematic division of knowledge by scientific organization, made a posteriori; the fractionation of contents follows the logic of the theory of knowledge, in their disciplines. These are more related to the objects of study and to its own research methods; This path leads to the contemplative perspective of "learning by learning" and "knowing by knowing".

In the second case, earth studies beneficiate from the systemic or holistic approach, follow the logic of the (1) proximity of the challenges that the student or his community faces or has to face, and (2) the familiarity with the resources to learn and to use the cognitive contents. The focus is the real problem, as "flooding areas": the goal is to learn all that is necessary to understand and solve the problem. In this case the path of education rests with the prospect of "learning to learn" and "know for using". Although these concepts and procedures are sometimes ambiguous, not fully consolidated, they are widely disseminated and researched (Chisholm et al. 2010).

In the first conventional approach, it is the fraction of the knowledge from a discipline, such as Geomorphology, which delimits the scope of the study of landscape forms, as defined in the textbooks. In the second approach it is a set of fractions of multidisciplinary knowledge (as in Hugget 1995), involving the object through the problems that it is involved. In the case of flood: where does it extend? How and when does occur? Is it an active alluvial plain? An alluvial fan system? How does it affect the community and how does the community interfere with frequency and extent? The system approach is more effective. The delimitation of the object and the depth of understanding of the learning project are given by the ability needed to solve the problem considered.

The important issues are not the internal questions of established knowledge. They are the exter- nal questions, as associated to the relationship of the students or their community with the subject. However, the approach will be supported by the available knowledge: so, the group will pick it up and evaluate its adequacy and applicability, under supervision and advisor of the teacher.

\section{Discussion: Purpose of Education in Earth Sciences}

The second dichotomy relates to the ultimate goal, or purpose, to be pursued through education: (1) apprehension and understanding of cognitive contents or (2) development of skills to deal with such content. Initially, it can be said that the two goals are equally important and the second depends on the first. However this dichotomy could be represented by confrontation between (1) the education oriented by techniques and procedures to achieve a practical and useful goal, versus (2) education oriented for the understanding of the fundamentals that explain or justify the technical or the procedure validation. The dichotomy becomes complete with the question: what should come first? The practice should come before theory? Yes, the practical problem is expected to come first.

As in the real world and in the construction of knowledge, first we take the problem, then the intuitive and empirical simple solutions, then the curiosity and investigation; at the end, the theoretical explanation and with their complex and possible solutions. In the scientific world, that looks like heresy. Certainly in frontier scientific research, the theory raises problems in the body of science that are investigated within the assumptions of theory.

However, no one should want children and young people, in the student world, to use the scientific method for the learning process or to be motivated to learn. This doesn't mean that teachers will neglect the practice of scientific method in the organization and development of lab or practical classes.

In the Earth Sciences, the establishment of objectives would not come from the components of the terrestrial spheres (objects), which have been unfolded into the various Cartesian disciplines. Instead, they must come from the major problems to mankind: hunger (food), water shortage, energy demand, raw materials need, environmental degradation, climate change and natural disasters. These earth concerns are the problems that affect dramatically, since small communities to entire nations. 
These problems put nations involved in wars; built and destroyed civilizations in the past. Focusing on these problems, the subjects of study can be identified. And their values may be accessed. What can Earth knowledge and investigation methods and techniques do in order to prevent, mitigate, supply, solve or save? A new design is needed for curricula, courses and class plans. The challenge is the "problem based learning" (see for example, Savin-Baden 2004; Vasconcelos e Almeida 2012).

This implies the study of the problem, to explore and to map it, to represent in its main components and the goals to reach; a plan or a project of work is designed and assumed by the learning group in order to reach the final selected objective and the document to be presented. The teacher, with his knowledge, experience and competence, is the guider, the coacher. The students are the players.

The mapping project of the last year of the Geology courses are a good practical example of collaborative learning based in the solution of a proposed problem. The experience could be introduced already in the first year. Intensive interaction and collaborative work with local institutions of public and private policy, services and productive sectors contributes to the perception and valuation of educational practices (STEM 2013).

The third dichotomy concerns the deductive or inductive procedure to be adopted in generating learning opportunities. In the first case it is general knowledge - as for example world physical geography (or the big rivers of the world) to reach the particular, the physical geography of the county (or the local gorge). In the second, the delimitation of physical geography is dispensable. The goal may be the local world in which we live: but the beginning is the land and the gorge around the school, recognizing her features and occupation, the images, the seasons, the processes, the rain, natural disasters etc. Then it extends to the county, to the region and to the continent, oceans etc. On rocks, do not start with the general classification, but the identification, characterization and use of the rocks in the neighborhood.

So, what are the practical problems in Earth Sciences, related to life quality and sustainability, about food production, energy, water, raw materials, climate changes and environment? As political decisions are needed to anticipate problems, the important issues of Earth Sciences to be analyzed and studied in all curricula from primary to gra- duation may be about soil conservation, fertilizers, renewable energy, water supply and quality, recycling and new material uses and sources, extreme events, nature cycles and disasters, environment protection and recuperation, gaseous, liquid and solid disposal in underground reservoirs. People, well informed, must be involved in decisions.

Some subjects will be preferred: weathering and landscapes, rock formation and mineral resources, aquifers and running water, coastal dynamics, ocean and atmospheric fluxes, earth internal and external energy sources, these are some subjects to be studied in earth sciences courses. Going further on subjects: slope systems; hydrographic basins; wetland systems; coastal systems, sedimentary basins, magmatic arcs, volcanic chains; mountain belts, continental collisions etc. Nearly all earth science subjects may be studied under a different perspective; the perspective of a student and earth citizen. Not in the perspective of the scientist or of the constructed theories and paradigms, although you may or may not arrive there!

It's the competence to solve problems that should be prioritized goals in learning, Comprehension and solutions of scientific problems and reasoning are challenges for researchers; for citizens and professionals the challenges are the scientific solution for real problems.

This is not a small or meaningless difference! It is meaningful and will propagate throughout the student and teacher's activity. The focus in basic science problems leads the student misunderstanding, undervaluation and the development of a rejection of the world of mathematics and science. Only the teacher would recognize the values of these scientific goals. To the students, they are a conceptual and operational sequence of ideas, methods and implementing tools of unreachable and unrecognized value - except to cross the boundary of examination and then forget them.

The debate about the most appropriate formulations seems innocuous, because the arguments come from different perspectives: the traditional experience versus the perception of the changing world. In addition, each argument has a higher or lower value depending on which time of the educational process is prevailing: if it is the academic, scientific, or construction of the encyclopedic enrichment, then the vision of student apprentice, the disciplinary subdivision and the deductive formulation will be prevalent. If it is the one of the motivation and the usefulness of knowledge, for which 
the student is the subject of learning, then the search for skills and inductive learning will predominate.

The change to the belief that the systemic or holistic mode could incorporate the first at specific times, seems reasonable, for being more general, comprehensive and not limited by the conventions of rationalism and reductionism of disciplinarily. Furthermore it facilitates multi-disciplinary approach and the appropriation of knowledge through group work, with the use of different sources and methods. Additionally it is more motivating by the fact of engaging students through their own challenges.

\section{Conclusions}

Severe changes are remolding the society in all sectors. Education has withstood change in a manner incompatible with what is happening in society. Course curricula, disciplines, classes and teacher behavior are nearly the same as fifty years behind. Education in environmental issues was not effective in nature occupation: regions with high risk to natural disasters are being occupied; pristine regions are being degraded by intense and abusive use. Intrinsic value of lands and their mineral resources have been discarded and commercial value of production is mistaken as the main drive mechanism of development. Susceptibility to large impacts of nature changes and disasters is growing. The fault lies in the ignorance about the earth dynamics and boundary conditions of equilibrium in natural systems, around us.

Education in Earth Sciences or its absence in basic education and most undergraduate courses have failed to empower people to decide how to do and how to manage the regional and local use of resources in a sustainable way. These subjects become the needs for al basic cycles at all levels of education.

The many changes in society impose new focus in education:
So this is my proposal: we will study the problem and write the research plan in ten planned sections of work, with forty total hours; in this first section we will define the working groups, with which you can share tasks, doubts and solutions. But each one will choose the problem to address based on their interest in knowledge and skills to acquire. We have, at three levels - class, course and project, to answer five questions: What? How? Where? Who? When? For the project, two additional questions have to be considered: How much? And for whom? Or, so what? As a matter of course, we will have to evaluate continuously our performance. Let's work?".
- The expressive availability of specialized software and tools makes it unnecessary to learn previously mathematical, physical and chemical fundamentals to perform highly efficient data acquisition, analysis and processing; this means a reduced demand for knowledge so strongly rejected in the so called basic cycles.

- The prevalence of values on results and objectives rather than operations, techniques and means, make clearer decisions on what goals to achieve, in terms of competence, the objectives of courses, disciplines and classes; and not in knowing concepts and theories.

- Progressive learning from objective, simple, particular, and familiar concepts toward generalized relationships, in depth and breadth, is easier to follow than the opposite path as in deductive reasoning.

- The high demand for freedom, autonomy and indiscipline in young people leads to different motivations for dedication to learning, and the main motivations are autonomy and sharing of the search for real problem solving or the approach based on learning problems and

\begin{tabular}{c|c|c|c|c|c}
\hline (C) Terrae Didat. & Campinas, SP & v.14 & n.3 & $289-295$ & jul./set. 2018 \\
\hline
\end{tabular}


performing projects (Fig. 1).

- The immense availability of encyclopedic and instructive knowledge, dispensing the teacher's discourse, requires learning to critically find the cognitive content and to deal with, or competence for use the concept, the relation, the techniques in practical purposes, mainly with respect to sustainability.

- In order to deal with the real world, its proble$\mathrm{ms}$, its values and its interactions, a systemic multidisciplinary view is required as basic education; natural objects can be approached, studied and transformed within the vision of natural systems, overcoming the limitations of the reductionist and mono-disciplinary view.

\section{References}

Chaves A.A. org. 2017. A Neurobiologia do Aprendizado na Prática. Ed. Alumnus. Digital version. https:// books.google.com.br/books.

Chisholm L., Fennes H., Karsten A., Reich K. 2010. Learning to learn: a method in action. Synthesis Report. European Commission. 38p. URL: https://www.uibk.ac.at/bgl/projects_networks/ 121/1121-literature-review-synthesis-report.pdf. (ac. Dez/2016).

Druker P.F. 2002. Managing in the Next Society. Butterworth-Heinemann. 321p. (Business \& Economics).

Freire P. 1996. Pedagogia da autonomia: saberes necessários à prática educativa. São Paulo: Ed. Paz e Terra.

Gardner H. 1983. Frames of mind: the theory of multiple intelligence. New York, Basic Books.

Houde J. 2006. Andragogy and Motivation: An Examination of the Principles of Andragogy through Two Motivation Theories. Online Submission, Paper presented at the Academy of Human Resource
Development International Conference (AHRD) (Columbus). p. 90-97 (Symp. 4-3). URL: http://www.eric.ed.gov/contentdelivery/servlet/ ERICServlet?accno=ED492652.

Hugget R. 1985. Earth Surface Systems. Springer-Verlag. $270 \mathrm{p}$.

Huggett R.J. 1995. Geoecology. Environmental Change: the evolving ecosphere. London, Routledge. 404p.

Gardner H. 2011. The Theory of Multiple Intelligences: as Psychology, as Education, as Social Science. Univ. Madrid. URL: https://howardgardner01.files. wordpress.com/2012/06/473-madrid-oct-22-2011. pdf.

Knowles M.S., Holton E.F., Swanson R.A. 1998.The adult learner: The definitive classic in adult education and human resources development. 5 ed. Houston, Gulf.

Maslow A.H. 1943. Theory of Human Motivation. Psychological Review, 50:370-396.

Savin-Baden M. 2004. Understanding the impact of assessment on students in Problem-Based Learning. Innovations in Education and Teaching International, 41(2):221-233.

STEM 2013. Federal Science, Technology, Engineering, and Mathematics (STEM) Education 5-Year Strategic Plan. A Report from the Committee on STEM Education National Science and Technology Council. URL: http://www.whitehouse.gov/ sites/default/files/microsites/ostp/pcast-stemedreport.pdf.

Tofler A. 1980. A Terceira Onda. Trad. J. Távora, 1982. Ed. Record. 491p.

Trefil J.S., Hazen R.M. 1995. The Sciences: An Integrated Approach. $1^{\text {st }}$ vol. The Sciences, an integrated approach. John Willey \& Sons. 343p.

Usher R. 2013. Experiência, pedagogia e práticas sociais. In: Illers K. org. 2013. Teorias contemporâneas da aprendizagem. Porto Alegre: Penso.

Vasconcelos C., Almeida A. 2012. Aprendizagem baseada na resolução de problemas no ensino das ciências: Propostas de trabalho para Ciências Naturais, Biologia e Geologia. Coleção Panorama. Porto: Porto Ed. $127 \mathrm{p}$.

\begin{tabular}{c|c|c|c|c|c}
\hline (C) Terrae Didat. & Campinas, SP & v.14 & n.3 & $289-295$ & jul./set. 2018 \\
\hline
\end{tabular}

